\title{
A Note on Michelacci and Zaffaroni, Long Memory, and Time Series of Economic Growth
}

\author{
Gerald Silverberg $^{\mathrm{a}, \mathrm{b}} \&$ Bart Verspagen ${ }^{\mathrm{a}, *}$ \\ ${ }^{a}$ ECIS, Eindhoven University of Technology \\ PO Box 513, 5600 MB Eindhoven, The Netherlands \\ ${ }^{\mathrm{a}}$ MERIT, University of Maastricht, \\ PO Box 616, 6200 MD Maastricht, The Netherlands \\ ${ }^{\mathrm{b}}$ International Institute of Infonomics \\ PO Box 2606, 6401 DC Heerlen, The Netherlands
}

We thank Per-Botolf Maurseth for running the Stata-scripts used in Tables 7 and 8.

\begin{abstract}
In a recent paper in The Journal of Monetary Economics, Michelacci and Zaffaroni (2000) estimate long memory parameters for GDP per capita of 16 OECD countries. In this note we argue that these estimations are questionable for the purposes of clarifying the time series properties of these data (presence of unit roots, mean reversion, long memory) because the authors a) filter out a deterministic linear-in-logs trend instead of first-differencing in logs, and manipulate the data in other highly questionable ways, b) rely on the semiparametric Geweke and Porter-Hudak (GPH) method as modified by Robinson, which is known to be highly biased in small samples. We re-examine these results using Beran's nonparametric FGN estimator and Sowell's exact maximum likelihood ARFIMA estimator. These methods avoid the small-sample bias and arbitrariness of the cut-off parameters of Robinson's method and allow us to control for short memory effects, although the parametric ARFIMA estimator introduces specification problems of its own. We also look at the influence of the choice of sub-periods on the results. Finally, we apply Robinson's method to our treatment of the data and show that MZ's results no longer hold, nor are their cut-off parameter and filtering insensitivity claims substantiated.
\end{abstract}

JEL classification: $\mathrm{C} 22, \mathrm{~N} 10, \mathrm{O} 4$

Keywords: long memory, economic growth

* Corresponding author: Tel 31-40-2475613, Fax 31-40-2474646, email: b.verspagen@tm.tue.nl 


\section{Introduction}

The time-series properties of the economic growth process have been at the center of a vigorous theoretical and methodological debate since the seminal paper by Nelson and Plosser (1982) on unit roots. This debate seems to shed less light on economic growth per se than on the pitfalls of econometric modelling: that the choice and interpretation of econometric methods are still too subject to objections and caveats to bear the weight of the conclusions many authors would like to place on them. It is therefore necessary to exercise the utmost care in the use of empirical methods.

In a recent paper Michelacci and Zaffaroni (2000) (referred to as MZ in the following) attempt to reconcile apparently contradictory stylized facts about the presence of unit roots, beta convergence, and long-term exponential trends by invoking the possibility of long memory in the growth process. While we welcome this as a highly stimulating contribution to the growth and convergence literature, the theoretical rationale and implications of long memory are not the subject of this note. ${ }^{1}$ Our purpose here is rather to question the methodology MZ employ and compare their results with our own deriving from the same data but based on, as we shall argue, superior (if still not completely unobjectionable) econometric methods.

MZ employ an estimator of the long memory parameter proposed by Geweke and PorterHudak (1983) and further developed by Robinson (1995). This estimator is based on fitting a linear regressor to the log-log plot of the periodogram vs. frequency at low frequencies. Two rule-of-thumb cut-off parameters are employed in this otherwise nonparametric process to determine how many components of the periodogram to use. ${ }^{2}$ Monte Carlo simulations have demonstrated conclusively ${ }^{3}$ that this estimator is biased in small samples. If short memory is also present in the data (due to AR and MA terms), it is also well known that the results will be contaminated unless short memory is controlled for.

MZ actually subject their raw data to two 'filtering' steps before testing for long memory. The specification of these steps is relegated to an appendix, where their motivation and implications still remain somewhat unclear. The first step is to subtract an exponential trend (either country specific or common). MZ assert but do not prove that "the memory of the process is entirely reflected in the residuals" by appealing to Nelson and Kang (1981), but we do not find this reference really germane to the issue at hand, nor the argument at all convincing. The second step consists of fractionally differencing the residual by $1 / 2$ in order to move the estimates into the region of validity of Robinson's asymptotic test statistic. Two objections can be made here. First, as the authors observe, fractionally differencing by $1 / 2$ entails an approximation and loss of data since only a finite number of terms of the infinite series representation of the differencing operator can be used, and the series must be initialized with (in their case) 10 observations. We are asked in a footnote to take it on trust that this does not introduce any bias into the test. It is also asserted that the results are 'generally robust' to the choice of the degree of differencing. But if this is the case, why not simply difference by one and avoid the approximation problem entirely (we cannot follow their arguments here concerning the obscuring of the distinction between conditional and unconditional convergence)? Furthermore, if we are free to difference the series as we like, Robinson's restriction of his statistic to $d \leq 1 / 2$ makes no sense, since any time series could be

\footnotetext{
${ }^{1}$ We hope to deal with long memory in the context of convergence in a future paper. Some preliminary results can be found in Silverberg and Verspagen (1998).

${ }^{2}$ For this reason methods such as the GPH estimator are usually referred to as semiparametric.

${ }^{3}$ See for example Sowell (1992b), Hauser et al. (1999), Agiakloglou et al. (1992), Cheung (1993), Hurvich and Beltrao (1994), Hurvich et al. (1998) and Janacek (1982).
} 
shifted to the range of validity using this invertible transformation, thus removing the restriction. Thus legitimate questions remain concerning the extent to which the main results are influenced by nontrivial data filtering techniques the authors would have us believe are of no import.

Our intention in this note is to examine the long memory properties of GDP of various countries in the Maddison (1996) dataset directly. Our methodology differs from MZ in the following respects:

1. Instead of subtracting a trend (however selected) and fractionally differencing, we simply first difference the (log) series, as is usual in the long memory literature.

2. To avoid the problems associated with the GPH/Robinson 'semiparametric' parameters and small-sample bias, we employ the nonparametric FGN estimator due to Beran (1994).

3. To tackle the short memory contamination problem and small-sample bias, we employ Sowell's (1992a) parametric maximum likelihood ARFIMA estimator as implemented by Doornik and Ooms (1996).

We then re-apply MZ's Robinson estimator to our treatment of the data to investigate the effects of the assumptions underlying MZ's methodology on their results.

\section{Long Memory in Economic Growth}

Studies of long memory in real output indicators commenced with Diebold and Rudebusch (1989) and Haubrich and Lo (1989). The former authors examined a number of US output time series using a two-stage process based on the GPH estimator to determine the degree of fractional integration, and an approximate maximum likelihood ARMA on the filtered residuals to handle the short memory aspect. They found significant evidence of long memory in these series. In contrast, Haubrich and Lo, using Lo's modified rescaled range estimator, found no evidence for long memory in a quarterly time series of post-war US data, as opposed to using the unmodified R/S statistic. Both of these studies suffer, however, from the estimation problems raised subsequently in numerous Monte Carlo studies (see footnote 3). In particular, they suffer from small-sample bias and short-memory contamination.

These estimation problems can be circumvented to some extent by employing a maximum likelihood estimator of the parametric ARFIMA model. Sowell (1992b) re-examined postwar US quarterly real GNP with the exact maximum likelihood estimator, nesting deterministic trend and unit root models within the ARFIMA model. He reported a significantly smaller estimate of the fractional parameter than Diebold and Rudebusch (1989) due to the bias of the latter method. He concludes that the data are consistent with both trend models. In fact, the best model according to Aikake's information criterion (AIC) from a set of estimations with $p$ and $q$ ranging from 0 to 3 is $\operatorname{ARFIMA}(3,-0.59,2)$.

In this note we will employ the same annual dataset due to Maddison (1995) as did MZ. The attraction of this dataset is that the data extend considerably further back in time and encompass a larger number of countries, ostensibly on a consistent basis, than the post-war (quarterly) US dataset used by previous authors. The time periods covered are not uniform across countries, however, and because of the time-aggregation problem of the fractional integration parameter, estimates based on annual and quarterly data are not immediately comparable. Our first test of long memory was proposed by Beran (1994), based on the Whittle approximate maximum likelihood method. This test models the time series under consideration as a fractional Gaussian noise (FGN) process, and estimates the Hurst parameter $h(=$ fractional integration parameter $d+1 / 2)$. A value of $h$ equal to 0.5 indicates no 
persistence (i.e., Gaussian white noise), while a value larger (smaller) than 0.5 indicates (anti) persistence. We use Beran's software, which is coded in S+, and is available from the appendix of his book.

Tables 1 to 5 document the results for both GDP and GDP per capita, both series being first differenced in logs to remove the obvious nonstationarity. We used the standard deviation of the estimated $h$ parameter provided by Beran's program to calculate a $t$-statistic for the null hypothesis $h=0.5$. $^{4}$

\section{[insert Table 1 about here]}

Table 1 gives the results for GDP per capita, using the complete sample period. For the 29 countries, we find 8 cases for which $h>0.5$ at the $1 \%$ confidence level, another 5 cases at the 5\% level, and 3 cases with 10\% significance. There are two cases (India, New Zealand) for which we find antipersistence $(h<0.5)$ significant at the $10 \%$ level. Thus, in 16 out of 29 cases we find $h>0.5$, so that approximately $60 \%$ of all countries display long memory for GDP per capita, with two displaying antipersistence.

Visual inspection of the time series reveals that in many cases the Second World War had a major impact on (per capita) GDP. In the US, as well as in some other countries, the war led to a major boom in GDP, while especially in the European countries, output collapsed in the 1940 - 1945 period due to war destruction. Also, the periods immediately before and after the war are very different, with the Great Depression sweeping through the world in the 1930s, while the 1950 - 1970 period was generally one of high growth and significant catching-up to the United States, the only participant in the war to emerge physically and institutionally unscathed (in Maddison's terms, this is the 'golden age' of capitalism).

This led us to investigate our hypothesis for the pre- and post-war period separately, as well as for the complete period, excluding the war. For this purpose, we took 1937 and 1950 as demarcation years, i.e., we defined the pre-war period as the period up to (and including) 1937, and defined the post-war period as the period from 1950 (inclusive) onwards. ${ }^{5}$ We thus obtain three new time series: one for the pre-war period, one for the post-war period, and one in which we concatenate these two periods. Note that the latter procedure is somewhat artificial, as it involves pasting together the years 1937 and 1950 (which in many countries represented similar levels of income). While this procedure may appear a bit unorthodox, it does provide a handy device for testing to what extent the war years alone influence the detection of long memory in the series.

\section{[Insert Table 2 about here]}

The results for these three additional cases are documented in Tables 2 - 4. For the pre-war period, documented in Table 2, we find very little evidence for long memory in GDP per capita. Of the 11 cases which show results significant at the $10 \%$ level or better, five cases point to antipersistence $(h<0.5)$ : Denmark, France, India, Japan, and the Netherlands. The cases for which we find significant long memory in the pre-war period are Austria (1\% level), Finland, the UK and Indonesia (5\% level) and Switzerland and Venezuela (10\% level).

4 Beran shows that this ' $t$-statistic' is asymptotically $N(0,1)$. We use a two-sided test of $h=0.5$ to detect departures in the direction of both persistence and antipersistence.

5 The years 1937 and 1950 are inclusive, which, in terms of first differences, means that the last datapoint in the pre-war period is the difference between GDP in 1937 and 1936, while the first datapoint of the post-war period is the difference between 1950 and 1949. 
[Insert Table 3 about here]

The post-war period is a different story. We find 21 cases (i.e., a large majority) with significant long memory, and only one case of significant antipersistence. Most of the results are significant at the $1 \%$ (10 cases) or $5 \%$ ( 7 cases) levels.

\section{[Insert Table 4 about here]}

Table 4 documents the results for the time series when we leave out the war years. This yields 14 cases with significant ( 8 cases at the 1\% level, two at the 5\% level, four at the $10 \%$ level) long memory, and one case with significant antipersistence (5\%, India).

While the results for the different subsamples are often consistent for many countries, there are a number of interesting exceptions. Denmark is significantly antipersistent pre-war, but essentially Gaussian for all other samples. In contrast, Spain is highly significantly persistent except for the pre-war period. Japan and the Netherlands are antipersistent pre-war, persistent post-war, but neither over the larger samples. On the basis of the FGN test alone, one might venture the hypothesis that as countries moved from a peripheral, semi-industrial status to an industrial one in the world economy their growth dynamics shifted from antipersistent to persistent, or at least that the value of their Hurst parameter increased.

The results for time series including or excluding the Second World War years in the full sample period are also consistent, with the major exception of the United States, which loses its highly significant long memory result (1\% level) by excluding the war years, even though long memory is also confirmed for the post-war years (but only at the $10 \%$ level).

[Insert Table 5 about here]

Although we feel that GDP per capita is a better indicator of economic growth, we also report results based on GDP without correcting for population growth. This follows more closely the approach taken by previous studies of long memory in aggregate output as well as the literature on unit roots in GDP data. Table 5 reports these results, which we only document for the full period (including the war). The results are significant in 16 cases (12 at the $1 \%$, four at the 5\% level). In general, the results are consistent with those for GDP per capita over the whole period. The four exceptions to this are India and Korea, for which we found (weakly) significant persistence in GDP per capita but no significant result for GDP; Mexico, for which we found no significant long memory in GDP per capita but a significant value for GDP; and New Zealand, which showed antipersistence in the case of GDP per capita, but no significant result in the case of GDP. New Zealand is also a curious case because antipersistence is only detected in the post-war subperiod.

Overall, these results seem to indicate that long memory models may be useful for describing fluctuations in aggregate output. However, the presence of long memory in both test models seems to depend to a considerable extent on its occurrence in the post-war rather than in the pre-war period, as well as the effect of the war years. This may be partly due to the quality of the data, which is generally better for the post-war period. However, one should not exclude the possibility that a structural break internal to some of these countries, or a more general change in the post-war economic regime, is responsible for this result. There are certainly enough institutional and other circumstances that changed to account for such a break (e.g., the Bretton Woods system, the Cold War and the 'Pax Americana'; see Maddison 
1991 for a more detailed account of the changing economic environment over the time span for which we have data).

We then re-examine these results using an ARFIMA model to control for short memory. The ARFIMA model is implemented using the software of Doornik and Ooms (1996), which uses Sowell's (1992a) exact full maximum likelihood method. ${ }^{6}$ These ARFIMA models were implemented for all combinations of ARMA parameters in the range 0..4.

We do not document all the ARFIMA results for reasons of space, but instead limit the documented results to two cases: one where the ARMA parameters are both set to zero, and the one producing the highest Aikake Information Criterion (AIC). The full set of results is available from the authors on request. The results for the ARFIMA approach differ substantially from those using the FGN model documented above. In fact, in the majority of cases where we find persistence using the FGN test, we do not find it in the ARFIMA model. Table 6 summarizes the ARFIMA results for the full time series and compares them with the corresponding FGN results and the fractional integration parameter estimated by the ARFIMA method constrained to $p=q=0$ (i.e., disregarding short memory). The FGN and constrained ARFIMA estimators are largely consistent (a regression of the latter on the former yields $y=1.192 x-0.047$ with $\left.R^{2}=0.9498\right)$.

[Insert Table 6 about here]

The weaker results obtained with the ARFIMA model may well result from the problems with this model in estimating persistence identified by Hauser et al. (1999) due to overparametrization and mis-specification. The ARFIMA estimates for different orders of the ARMA terms vary greatly. Hauser et al. (1999) show that this can lead to a downward bias of the estimates of persistence. We are also confronted with a specification problem, since the ARFIMA estimator is known to be unbiased and consistent only for the correct specification of the short memory parameters. To select the 'correct' model, we have relied on the AIC, but nonetheless one has to regard these results with a fair degree of scepticism due to the extreme sensitivity of the results to specification error.

Finally, we have estimated the fractional differencing parameter using the same method as MZ, namely Robinson's semi-parametric Gaussian test, on our treatment of the dataset. ${ }^{7}$ This exercise serves two purposes. First, it enables us to see to what extent MZ's results derive from their peculiar data filtering, and second, to determine the sensitivity of the estimations to the choice of the two cut-off parameters.

\section{[Insert Table 7 about here]}

Table 7 summarizes the Robinson estimates on our complete period data (first difference of $\operatorname{logs}$ of GDP per capita) using the same cut-offs as $\mathrm{MZ}$ (power $=0.525, l=2$ ). The results are at variance with both MZ's (whose estimates were systematically in the range 0.5 to 1 ) and our own previous results. Only three countries now display significant long memory, but then only at the $10 \%$ level, and two of the three are anti-persistent. This demonstrates conclusively that MZ's main conclusion is an artefact of the multi-staged data filtering they apply to the Maddison data. Thus the long memory properties of the data, contrary to MZ's claim (p. 151, fn 16), are not preserved under detrending and fractional differencing.

\footnotetext{
${ }^{6}$ We also experimented with Beran's ARFIMA software, which applies the Whittle approximate maximum likelihood method. The results were similar and are available from the authors on request.

${ }^{7}$ To this end we employed a Stata script developed by Christopher F. Baum and Vince Wiggins available at http://ideas.uqam.ca/ideas/data/Softwares/bocbocodeS411001.html.
} 
[Insert Table 8 about here]

Table 8 reproduces these estimates for 'default' values of the cut-off parameters (power $0.9, l=0)$. The results are now more or less consistent with Beran's non-parametric FGN estimator and the parametric ARFIMA estimator when the short-memory parameters are constrained to zero (see Table 6). Most of the results match in terms of sign and significance, if not very closely in actual estimated value, with a few exceptions. While it is somewhat reassuring that Robinson's semi-parametric estimator is reasonable consistent with other methods, comparison with Table 7 shows that MZ's claim that “...the empirical results are very robust to changes in the choice of the trimming and the bandwidth" (p. 152) is clearly violated.

\section{Concluding Remarks}

At first view, our statistical tests establish a strong case for pervasive but not universal long memory in time series of individual countries. The results must be relativized, however, because of their dependence to some extent on the subperiod examined and on the salient effect of the Second World War. While the effects of short memory can be separated out from those of long memory by employing maximum likelihood ARFIMA estimators, these models also yield much less favorable evidence of long memory, and are subject to specification error.

However, there is no evidence for fractional integration in the range $(0.5,1)$, an essential point in ZM's argument in the context of beta convergence (mean reversion, nonstationarity). In fact, allowing for short memory, the evidence for persistence is very weak indeed, and antipersistence is as common as persistence. In our opinion, MZ's results are probably artefacts of their detrending and data filtering techniques (described in their Appendix A.1) and the specific choices of cut-off values of the Robinson semi-parametric method and the small-sample bias of the method itself. Contrary to their claim, we find that tests of long memory are highly sensitive to such factors. Moreover, the choice of estimator and the sample period examined also critically influenced the detection of long memory. These ambiguities will remain until such time as a truly unobjectionable test for long memory is developed.

\section{References}

Agiakloglou, C., Newbold, P., Wohar, M., 1992, "Bias in an estimator of the fractional differencing parameter", Journal of Time Series Analysis, 14: 235-246.

Baillie, R., 1996, "Long Memory Processes and Fractional Integration in Econometrics", Journal of Econometrics, 73: 5-59.

Beran, J., 1994, Statistics for Long-Memory Processes, New York: Chapman \& Hall.

Cheung, Y.W., 1993, "Tests for Fractional Integration: A Monte Carlo Investigation", Journal of Time Series Analysis, 14: 331-345.

Diebold, F.X. and Rudebusch, G.D., 1989, "Long Memory and Persistence in Aggregate Output", Journal of Monetary Economics, 24: 189-209.

Doornik, J.A. and M. Ooms, 1996, "A Package for Estimating, Forecasting and Simulating ARFIMA models", mimeo description of Ox ARFIMA package, Nuffield College, Oxford and Erasmus University, Rotterdam. 
Geweke, J. and Porter-Hudak, S., 1983, "The Estimation and Application of Long Memory Time Series Models", Journal of Time Series Analysis, 4: 221-238.

Haubrich, J.G. and Lo, A.W., 1989, "The Sources and Nature of Long-Term Memory in the Business Cycle", Cambridge, MA: NBER Working Paper No. 2951.

Hauser, M.A., 1998, "Maximum Likelihood Estimators for ARFIMA Models: A Monte Carlo Study", Working paper, University of Economics and Business Administration, Department of Statistics, Vienna, forthcoming in Journal of Statistical Planning and Inference.

Hauser, M.A., Pötscher, B.M. and E. Reschenhofer, 1999, "Measuring Persistence in Aggregate Output: ARMA Models, Fractionally Integrated ARMA Models and Nonparametric Procedures", Empirical Economics, 24: 243-269.

Hurvich, C.M., Beltrao, B.K., 1994, "Automatic Semiparametric Estimation of the LongMemory Parameter of a Long-Memory Time Series", Journal of Time Series Analysis, 15: 285-302.

Hurvich, C.M., Deo, R., Brodsky, J., 1998, "The Mean Square Error of Geweke and PorterHudak's Estimates of the Memory Parameter of a Long Memory Time Series", Journal of Time Series Analysis, 19: 19-46.

Janacek, G.J., 1982, "Determining the Degree of Differencing for Time Series via the Log Spectrum", Journal of Time Series Analysis, 3: 177-183.

Lo, A.W., 1991, "Long Term Memory in Stock Market Prices", Econometrica, 59(5): 1279-1314.

Maddison, A., 1995, Monitoring the World Economy 1820-1992, Paris: OECD.

Michelacci, C. and Zaffaroni, P., 2000, "(Fractional) Beta Convergence", Journal of Monetary Economics, 45: 129-153.

Nelson, C.R. and Plosser, C.I., 1982, "Trends and Random Walks in Macroeconomic Time Series: Some Evidence and Implications", Journal of Monetary Economics, 10: 139-162.

Sowell, F.B., 1992a, "Maximum Likelihood Estimation of Stationary Univariate Fractionally Integrated Time Series Models", Journal of Econometrics, 53: 165-188.

Sowell, F.B., 1992b, "Modeling Long-Run Behavior with the Fractional ARIMA Model", Journal of Monetary Economics, 29: 277-302. 
Table 1. Estimation results for long memory tests, GDP per capita, complete period, FGN model using Beran-Whittle estimation algorithm

\begin{tabular}{|c|c|c|c|}
\hline Country & $\mathrm{N}(\mathrm{obs})$ & Est. $\mathrm{h}$ & $\mathrm{t}(0.5)$ \\
\hline Argentina & 94 & 0.5252 & 0.39 \\
\hline Australia & 124 & 0.5108 & 0.19 \\
\hline Austria & 124 & 0.5296 & 0.52 \\
\hline Belgium & 124 & 0.6357 & $2.33 * *$ \\
\hline Brazil & 94 & 0.6110 & $1.67 *$ \\
\hline Canada & 124 & 0.6417 & $2.43 * *$ \\
\hline Switzerland & 95 & 0.6604 & $2.40 * *$ \\
\hline Chile & 94 & 0.4118 & -1.42 \\
\hline Colombia & 69 & 0.6158 & 1.49 \\
\hline Germany (West) & 124 & 0.6945 & $3.30 * * *$ \\
\hline Denmark & 124 & 0.4833 & -0.30 \\
\hline Spain & 94 & 0.7084 & $3.07 * * *$ \\
\hline Finland & 124 & 0.6567 & $2.68 * * *$ \\
\hline France & 124 & 0.6081 & $1.87 *$ \\
\hline United Kingdom & 124 & 0.7288 & $3.86 * * *$ \\
\hline India & 92 & 0.3926 & $-1.73 *$ \\
\hline Indonesia & 92 & 0.9263 & $6.05 * * *$ \\
\hline Italy & 124 & 0.6491 & $2.55 * *$ \\
\hline Japan & 109 & 0.5745 & 1.22 \\
\hline South Korea & 81 & 0.6334 & $1.85 *$ \\
\hline Mexico & 73 & 0.6174 & 1.55 \\
\hline Netherlands & 124 & 0.5324 & 0.57 \\
\hline Norway & 124 & 0.5447 & 0.79 \\
\hline New Zealand & 124 & 0.3997 & $-1.87 *$ \\
\hline Peru & 81 & 0.4353 & -0.96 \\
\hline Sweden & 124 & 0.6416 & $2.43 * *$ \\
\hline Taiwan & 89 & 0.7293 & $3.76 * * *$ \\
\hline Venezuela & 94 & 0.76 & $3.80 * * *$ \\
\hline United States & 124 & 0.6766 & $3.01 * * *$ \\
\hline
\end{tabular}

One, two and three stars denote significance at the $10 \%, 5 \%$ and $1 \%$ levels, respectively, in a two-sided t-test. 
Table 2. Estimation results for long memory tests, GDP per capita, pre-war period, FGN model using Beran-Whittle estimation algorithm

\begin{tabular}{|c|c|c|c|}
\hline Country & $\mathrm{N}(\mathrm{obs})$ & Est. $\mathrm{h}$ & $\mathrm{t}(0.5)$ \\
\hline Argentina & 37 & 0.6215 & 1.14 \\
\hline Australia & 67 & 0.4377 & -0.84 \\
\hline Austria & 67 & 0.7911 & $3.58 * * *$ \\
\hline Belgium & 67 & 0.5405 & 0.52 \\
\hline Brazil & 37 & 0.3638 & -1.41 \\
\hline Canada & 67 & 0.6303 & 1.65 \\
\hline Switzerland & 38 & 0.6859 & $1.75 *$ \\
\hline Chile & 37 & 0.3905 & -1.12 \\
\hline Colombia & 12 & na & na \\
\hline Germany (West) & 67 & 0.4658 & -0.45 \\
\hline Denmark & 67 & 0.3539 & $-2.05 * *$ \\
\hline Spain & 37 & 0.5879 & 0.83 \\
\hline Finland & 67 & 0.6633 & $2.05 * *$ \\
\hline France & 67 & 0.3668 & $-1.86 *$ \\
\hline United Kingdom & 67 & 0.6786 & $2.24 * *$ \\
\hline India & 37 & 0.0858 & $-5.12 * * *$ \\
\hline Indonesia & 37 & 0.726 & $2.08 * *$ \\
\hline Italy & 67 & 0.5062 & 0.08 \\
\hline Japan & 52 & 0.1789 & $-4.48 * * *$ \\
\hline South Korea & 26 & na & na \\
\hline Mexico & 16 & na & na \\
\hline Netherlands & 67 & 0.3442 & $-2.20 * *$ \\
\hline Norway & 67 & 0.3877 & -1.55 \\
\hline New Zealand & 67 & 0.4941 & -0.08 \\
\hline Peru & 24 & na & na \\
\hline Sweden & 67 & 0.6268 & 1.60 \\
\hline Taiwan & 34 & na & na \\
\hline Venezuela & 37 & 0.6865 & $1.73 *$ \\
\hline United States & 67 & 0.5147 & 0.19 \\
\hline
\end{tabular}

One, two and three stars denote significance at the $10 \%, 5 \%$ and $1 \%$ levels, respectively, in a two-sided t-test. 
Table 3. Estimation results for long memory tests, GDP per capita, post-war period, FGN model using Beran-Whittle estimation algorithm

\begin{tabular}{|c|c|c|c|}
\hline Country & $\mathrm{N}(\mathrm{obs})$ & Est. $\mathrm{h}$ & $\mathrm{t}(0.5)$ \\
\hline Argentina & 45 & 0.5231 & 0.25 \\
\hline Australia & 45 & 0.6089 & 1.13 \\
\hline Austria & 45 & 0.7875 & $2.90 * * *$ \\
\hline Belgium & 45 & 0.6690 & $1.74 *$ \\
\hline Brazil & 45 & 0.8176 & $3.19 * * *$ \\
\hline Canada & 45 & 0.4872 & -0.14 \\
\hline Switzerland & 45 & 0.7138 & $2.18 * *$ \\
\hline Chile & 45 & 0.6246 & 1.29 \\
\hline Colombia & 45 & 0.7227 & $2.27 * *$ \\
\hline Germany (West) & 45 & 0.8275 & $3.28 * * *$ \\
\hline Denmark & 45 & 0.5097 & 0.10 \\
\hline Spain & 45 & 0.9065 & $4.04 * * *$ \\
\hline Finland & 45 & 0.8504 & $3.50 * * *$ \\
\hline France & 45 & 0.8365 & $3.37 * * *$ \\
\hline United Kingdom & 45 & 0.6974 & $2.02 * *$ \\
\hline India & 43 & 0.3968 & -1.13 \\
\hline Indonesia & 43 & 0.7243 & $2.23 * *$ \\
\hline Italy & 45 & 0.8287 & $3.29 * * *$ \\
\hline Japan & 45 & 0.9367 & $4.33 * * *$ \\
\hline South Korea & 43 & 0.5869 & 0.89 \\
\hline Mexico & 45 & 0.7664 & $2.69 * *$ \\
\hline Netherlands & 45 & 0.6885 & $1.93 *$ \\
\hline Norway & 45 & 0.7041 & $2.08 * *$ \\
\hline New Zealand & 45 & 0.2958 & $-2.44 * *$ \\
\hline Peru & 45 & 0.7867 & $2.89 * * *$ \\
\hline Sweden & 45 & 0.8630 & $3.62 * * *$ \\
\hline Taiwan & 43 & 0.7585 & $2.56 * *$ \\
\hline Venezuela & 45 & 0.6791 & $1.84 *$ \\
\hline United States & 45 & 0.6705 & $1.75 *$ \\
\hline
\end{tabular}

One, two and three stars denote significance at the $10 \%, 5 \%$ and $1 \%$ levels, respectively, in a two-sided t-test. 
Table 4. Estimation results for long memory tests, GDP per capita, war years excluded, FGN model using Beran-Whittle estimation algorithm

\begin{tabular}{|c|c|c|c|}
\hline Country & $\mathrm{N}$ & $\mathrm{h}$ & $\mathrm{t}(0.5)$ \\
\hline Argentina & 82 & 0.5495 & 0.71 \\
\hline Australia & 112 & 0.4825 & -0.30 \\
\hline Austria & 112 & 0.8211 & $5.08 * * *$ \\
\hline Belgium & 112 & 0.6074 & $1.77 *$ \\
\hline Brazil & 82 & 0.6419 & $1.98 *$ \\
\hline Canada & 112 & 0.6016 & $1.67 *$ \\
\hline Switzerland & 83 & 0.7009 & $2.79 * * *$ \\
\hline Chile & 82 & 0.4475 & -0.78 \\
\hline Colombia & 57 & 0.6030 & 1.21 \\
\hline Germany (West) & 112 & 0.6090 & $1.79 *$ \\
\hline Denmark & 112 & 0.4513 & -0.84 \\
\hline Spain & 82 & 0.7701 & $3.68 * * *$ \\
\hline Finland & 112 & 0.6939 & $3.13 * * *$ \\
\hline France & 112 & 0.4738 & -0.45 \\
\hline United Kingdom & 112 & 0.6812 & $2.93 * * *$ \\
\hline India & 80 & 0.3602 & $-2.14 * *$ \\
\hline Indonesia & 80 & 0.7474 & $3.34 * * *$ \\
\hline Italy & 112 & 0.6278 & $2.09 * *$ \\
\hline Japan & 97 & 0.6063 & 1.63 \\
\hline South Korea & 69 & 0.6621 & $2.06 * *$ \\
\hline Mexico & 61 & 0.6074 & 1.30 \\
\hline Netherlands & 112 & 0.4453 & -0.95 \\
\hline Norway & 112 & 0.5146 & 0.25 \\
\hline New Zealand & 112 & 0.4441 & -0.97 \\
\hline Peru & 69 & 0.4616 & -0.52 \\
\hline Sweden & 112 & 0.6797 & $2.91 * * *$ \\
\hline Taiwan & 77 & 0.6169 & 1.59 \\
\hline Venezuela & 82 & 0.7028 & $2.79 * * *$ \\
\hline United States & 112 & 0.5379 & 0.63 \\
\hline
\end{tabular}

One, two and three stars denote significance at the $10 \%, 5 \%$ and $1 \%$ levels, respectively, in a two-sided t-test. 
Table 5. Estimation results for long memory tests, GDP, complete period, FGN model using Beran-Whittle estimation algorithm

\begin{tabular}{|c|c|c|c|}
\hline Country & $\mathrm{N}(\mathrm{obs})$ & Est. $\mathrm{h}$ & $\mathrm{t}(0.5)$ \\
\hline Argentina & 94 & 0.5605 & 0.92 \\
\hline Australia & 124 & 0.5257 & 0.45 \\
\hline Austria & 124 & 0.5142 & 0.25 \\
\hline Belgium & 124 & 0.6428 & $2.45 * *$ \\
\hline Brazil & 94 & 0.6385 & $2.07 * *$ \\
\hline Canada & 124 & 0.6710 & $2.91 * * *$ \\
\hline Switzerland & 95 & 0.7100 & $3.11 * * *$ \\
\hline Chile & 94 & 0.4170 & -1.33 \\
\hline Colombia & 69 & 0.6189 & 1.53 \\
\hline Germany (West) & 124 & 0.7056 & $3.48 * * *$ \\
\hline Denmark & 124 & 0.4817 & -0.33 \\
\hline Spain & 94 & 0.7145 & $3.16 * * *$ \\
\hline Finland & 124 & 0.6613 & $2.75 * * *$ \\
\hline France & 124 & 0.6588 & $2.71 * * *$ \\
\hline United Kingdom & 124 & 0.7325 & $3.92 * * *$ \\
\hline India & 92 & 0.4953 & -0.07 \\
\hline Indonesia & 92 & 0.9317 & $6.11 * * *$ \\
\hline Italy & 124 & 0.6575 & $2.69 * * *$ \\
\hline Japan & 109 & 0.5688 & 1.13 \\
\hline South Korea & 81 & 0.6021 & 1.43 \\
\hline Mexico & 73 & 0.6748 & $2.28 * *$ \\
\hline Netherlands & 124 & 0.5428 & 0.75 \\
\hline Norway & 124 & 0.5447 & 0.79 \\
\hline New Zealand & 124 & 0.4971 & -0.05 \\
\hline Peru & 81 & 0.4394 & -0.90 \\
\hline Sweden & 124 & 0.6473 & $2.52 * *$ \\
\hline Taiwan & 89 & 0.7475 & $3.53 * * *$ \\
\hline Venezuela & 94 & 0.7561 & $3.74 * * *$ \\
\hline United States & 124 & 0.6798 & $3.06 * * *$ \\
\hline
\end{tabular}

One, two and three stars denote significance at the $10 \%, 5 \%$ and $1 \%$ levels, respectively, in a two-sided t-test. 
Table 6. Comparison of Fractional Integration Parameters Estimated with FGN, Constrained ARFIMA $(p=q=0)$ and Full ARFIMA Methods.

\begin{tabular}{|c|c|c|c|c|c|c|c|c|}
\hline \multirow[b]{2}{*}{ Country } & \multirow[b]{2}{*}{$\mathrm{N}$} & \multicolumn{2}{|c|}{ FGN $(\mathrm{d}=\mathrm{h}-1 / 2)$} & \multicolumn{2}{|c|}{$\operatorname{ARFIMA}(0, \mathrm{~d}, 0)$} & \multicolumn{3}{|c|}{$\operatorname{ARFIMA}(p, d, q)$} \\
\hline & & $\mathrm{d}$ & $\mathrm{t}(0)$ & $\mathrm{d}$ & $\mathrm{t}(0)$ & d & $\mathrm{t}(0)$ & $\mathrm{p}, \mathrm{q}$ \\
\hline Argentina & 94 & 0.0252 & 0.39 & -0.0249 & -0.25 & -0.8311 & $-4.58 * * *$ & 1,0 \\
\hline Australia & 124 & 0.0108 & 0.19 & 0.0026 & 0.04 & -0.0634 & -0.36 & 3,2 \\
\hline Austria & 124 & 0.0296 & 0.52 & -0.0064 & -0.08 & -0.2137 & -1.19 & 1,0 \\
\hline Belgium & 124 & 0.1357 & $2.33 * *$ & 0.1235 & 1.55 & 0.0578 & 0.72 & 2,2 \\
\hline Brazil & 94 & 0.1110 & $1.67 *$ & 0.1145 & 1.32 & 0.1145 & 1.32 & 0,0 \\
\hline Canada & 124 & 0.1417 & $2.43 * *$ & 0.1334 & 1.48 & -0.5611 & $-2.83 * * *$ & 1,0 \\
\hline Switzerland & 95 & 0.1604 & $2.40 * *$ & 0.1310 & 1.31 & -0.3282 & -1.08 & 1,0 \\
\hline Chile & 94 & -0.0882 & -1.42 & -0.2683 & $-2.29 * *$ & -0.5889 & $-3.39 * * *$ & 2,0 \\
\hline Colombia & 69 & 0.1158 & 1.49 & 0.0438 & 0.33 & -0.4924 & $-2.85 * * *$ & 2,3 \\
\hline West Germany & 124 & 0.1945 & $3.30 * * *$ & 0.1564 & 1.59 & -0.2009 & $-2.09 * *$ & 0,1 \\
\hline Denmark & 124 & -0.0167 & -0.30 & -0.0519 & -0.68 & -0.1057 & -1.32 & 1,1 \\
\hline Spain & 94 & 0.2084 & $3.07 * * *$ & 0.2388 & $3.02 * * *$ & 0.2217 & $2.50 * *$ & 2,2 \\
\hline Finland & 124 & 0.1567 & $2.68 * * *$ & 0.1306 & 1.51 & -0.0631 & -0.65 & 1,1 \\
\hline France & 124 & 0.1081 & $1.87^{*}$ & 0.0861 & 1.02 & -0.3574 & -1.41 & 4,3 \\
\hline UK & 124 & 0.2288 & $3.86^{* * * *}$ & 0.2221 & $2.32 * *$ & -0.0179 & -0.13 & 4,1 \\
\hline India & 92 & -0.1074 & $-1.73^{*}$ & -0.1163 & $-1.71 *$ & 0.1009 & 0.92 & 4,4 \\
\hline Indonesia & 92 & 0.4263 & $6.05^{* * *}$ & 0.4518 & $7.74 * * *$ & -0.5217 & -1.46 & 2,0 \\
\hline Italy & 124 & 0.1491 & $2.55^{* *}$ & 0.1408 & $1.71 *$ & -0.1071 & -0.65 & 1,0 \\
\hline Japan & 109 & 0.0745 & 1.22 & 0.0645 & 0.82 & 0.0645 & 0.82 & 0,0 \\
\hline South Korea & 81 & 0.1334 & $1.85^{*}$ & 0.1230 & 1.35 & 0.1230 & 1.35 & 0,0 \\
\hline Mexico & 73 & 0.1174 & 1.55 & 0.1200 & 1.32 & 0.1200 & 1.32 & 0,0 \\
\hline Netherlands & 124 & 0.0324 & 0.57 & -0.0108 & -0.13 & -0.1121 & -1.18 & 1,1 \\
\hline Norway & 124 & 0.0447 & 0.79 & 0.0369 & 0.52 & 0.0647 & 0.76 & 2,2 \\
\hline New Zealand & 124 & -0.1003 & $-1.87 *$ & -0.1702 & $-2.21 * *$ & -0.2286 & $-1.77 *$ & 2,3 \\
\hline Peru & 81 & -0.0647 & -0.96 & -0.1422 & -1.42 & 0.2280 & 0.59 & 4,3 \\
\hline Sweden & 124 & 0.1416 & $2.43^{* *}$ & 0.1269 & $1.65^{*}$ & 0.0059 & 0.06 & 4,4 \\
\hline Taiwan & 89 & 0.2293 & $3.76^{* * *}$ & 0.1969 & $2.07 * *$ & -0.0514 & -0.57 & 0,1 \\
\hline Venezuela & 94 & 0.2600 & $3.80 * * *$ & 0.2732 & $2.97 * * *$ & 0.1214 & 1.24 & 2,2 \\
\hline United States & 124 & 0.1766 & $3.01 * * *$ & 0.1272 & 1.27 & -0.6360 & $-3.19 * * *$ & 2,3 \\
\hline
\end{tabular}

Notes: Time series are first differences of logged GDP per capita. FGN results are included for comparison only and obtained using the estimated values for $h$ from Table $1, d=h-1 / 2$. ARFIMA results are obtained using Sowell's maximum likelihood estimator as implemented by Doornik and Ooms (1996). The ARFIMA(p,q,d) results are for the values of $\mathrm{p}, \mathrm{q}$ in the range $0 . .4$ which maximize the AIC. One, two and three stars denote significance at the $10 \%, 5 \%$ and $1 \%$ levels, respectively, in a twosided t-test. 
Table 7. Estimation results for long memory tests, GDP per capita, complete period, Robinson semi-parametric Gaussian test, power $=0.525, l=2$

\begin{tabular}{|c|c|c|c|}
\hline Country & $\mathrm{N}(\mathrm{obs})$ & Est. d & $\mathrm{t}(0)$ \\
\hline Argentina & 94 & 0.689 & $1.80 *$ \\
\hline Australia & 124 & -0.353 & 1.44 \\
\hline Austria & 124 & -0.472 & $2.08 *$ \\
\hline Belgium & 124 & 0.160 & 0.40 \\
\hline Brazil & 94 & -0.029 & 0.06 \\
\hline Canada & 124 & -0.229 & 0.58 \\
\hline Switzerland & 95 & 0.074 & 0.12 \\
\hline Chile & 94 & -0.775 & 1.71 \\
\hline Colombia & 69 & -0.404 & 0.58 \\
\hline Germany (West) & 124 & -0.403 & $1.92 *$ \\
\hline Denmark & 124 & 0.102 & 0.49 \\
\hline Spain & 94 & 0.255 & 0.67 \\
\hline Finland & 124 & 0.075 & 0.24 \\
\hline France & 124 & -0.155 & 0.76 \\
\hline United Kingdom & 124 & -0.361 & 1.40 \\
\hline India & 92 & 0.381 & 1.01 \\
\hline Indonesia & 92 & 0.005 & 0.02 \\
\hline Italy & 124 & -0.170 & 0.69 \\
\hline Japan & 109 & -0.193 & 1.37 \\
\hline South Korea & 81 & 0.550 & 1.06 \\
\hline Mexico & 73 & -0.043 & 0.04 \\
\hline Netherlands & 124 & -0.232 & 1.17 \\
\hline Norway & 124 & -0.358 & 1.05 \\
\hline New Zealand & 124 & 0.408 & 1.35 \\
\hline Peru & 81 & -0.633 & 0.91 \\
\hline Sweden & 124 & 0.080 & 0.24 \\
\hline Taiwan & 89 & 0.181 & 0.42 \\
\hline Venezuela & 94 & -0.465 & 1.66 \\
\hline United States & 124 & -0.487 & $1.77 *$ \\
\hline
\end{tabular}

One, two and three stars denote significance at the $10 \%, 5 \%$ and $1 \%$ levels, respectively, in a two-sided t-test. 
Table 8. Estimation results for long memory tests, GDP per capita, complete period, Robinson semi-parametric Gaussian test, power $=0.9, l=0$

\begin{tabular}{|c|c|c|c|}
\hline Country & $\mathrm{N}(\mathrm{obs})$ & Est. d & $\mathrm{t}(0)$ \\
\hline Argentina & 94 & 0.060 & 0.69 \\
\hline Australia & 124 & -0.019 & 0.27 \\
\hline Austria & 124 & -0.027 & 0.68 \\
\hline Belgium & 124 & 0.296 & $3.61 * * *$ \\
\hline Brazil & 94 & 0.292 & $2.42 * *$ \\
\hline Canada & 124 & 0.109 & 1.57 \\
\hline Switzerland & 95 & 0.220 & $1.71 *$ \\
\hline Chile & 94 & -0.365 & $2.87 * * *$ \\
\hline Colombia & 69 & 0.114 & 1.10 \\
\hline Germany (West) & 124 & 0.295 & $3.95 * * *$ \\
\hline Denmark & 124 & 0.065 & 0.96 \\
\hline Spain & 94 & 0.476 & $2.99 * * *$ \\
\hline Finland & 124 & 0.357 & $4.30 * * *$ \\
\hline France & 124 & 0.264 & $3.38 * * *$ \\
\hline United Kingdom & 124 & 0.267 & $2.93 * * *$ \\
\hline India & 92 & 0.278 & 1.59 \\
\hline Indonesia & 92 & 0.411 & $3.25 * * *$ \\
\hline Italy & 124 & 0.224 & $2.96 * * *$ \\
\hline Japan & 109 & 0.140 & $1.92 *$ \\
\hline South Korea & 81 & 0.340 & 1.25 \\
\hline Mexico & 73 & 0.038 & 0.40 \\
\hline Netherlands & 124 & 0.195 & $2.85 * * *$ \\
\hline Norway & 124 & 0.039 & 0.60 \\
\hline New Zealand & 124 & 0.094 & 0.97 \\
\hline Peru & 81 & -0.024 & 0.06 \\
\hline Sweden & 124 & 0.191 & $2.41 * *$ \\
\hline Taiwan & 89 & 0.231 & 1.53 \\
\hline Venezuela & 94 & 0.090 & 1.15 \\
\hline United States & 124 & 0.169 & 1.49 \\
\hline
\end{tabular}

One, two and three stars denote significance at the $10 \%, 5 \%$ and $1 \%$ levels, respectively, in a two-sided t-test. 